\title{
The Influence of the Spatial Scale on the Fishery Landings-SST Relationship
}

\author{
Fabio Pranovi *, Marco Anelli Monti, Daniele Brigolin and Matteo Zucchetta \\ Department of Environmental Sciences, Informatics and Statistics, Ca' Foscari University of Venice, Venice, Italy
}

Possible effects of the spatial scale of analysis on the relationship between fishery landings and the water temperature in the Mediterranean Sea have been investigated using the FAO capture database (1970-2010). The analysis was performed by dividing species in three thermal affinity categories: cold, temperate and warm-water species. Results showed significant changes in fishery landings composition during the last four decades, in terms of the relative contribution of cold, temperate and warm-water species to landings; moreover, the presence of a strong influence of water warming in determining the landings temporal pattern has been confirmed. This relationship, however, resulted to be not homogenous across the tested spatial scales (entire Mediterranean basin, three main sub-basins, eight FAO areas). The best models (based on the Akaike Information Criterion), were the ones fitted at the finer spatial definition (i.e., the eight FAO areas) for all

OPEN ACCESS

Edited by:

Dorte Krause-Jensen, Aarhus University, Denmark

Reviewed by:

Thorsten Johannes Skovbjerg Balsby, Aarhus University, Denmark

Angel Pérez-Ruzafa,

University of Murcia, Spain

*Correspondence:

Fabio Pranovi fpranovi@unive.it

Specialty section:

This article was submitted to Global Change and the Future Ocean,

a section of the journal Frontiers in Marine Science

Received: 29 February 2016 Accepted: 28 July 2016 Published: 10 August 2016

Citation:

Pranovi F, Anelli Monti M, Brigolin D and Zucchetta $M$ (2016) The Influence of the Spatial Scale on the Fishery Landings-SST Relationship.

Front. Mar. Sci. 3:143. doi: 10.3389/fmars.2016.00143 the three thermal affinity categories. The recorded relationship showed clear differences in terms of direction, depending on both areas and thermal affinity groups. Cold-water species showed a negative relationship with the increasing water temperature in all the FAO areas, being partially replaced by temperate-water ones, with the exception of the Adriatic and Black Sea (the coldest areas in the Mediterranean basin), where a moderate increase in the water temperature is still favoring the cold affinity group. This kind of results could be useful within the context of the management plans definition, within a context of climate changes.

Keywords: fishery, landings, climate changes, SST, spatial scale, Mediterranean Sea

\section{INTRODUCTION}

Climate changes represent the most pervasive and widespread driver affecting the ocean environment on a global scale, impacting marine communities, changing their structure and modifying the processes at the ecosystem level (Gilman et al., 2010; Hoegh-Guldberg and Bruno, 2010; Woodward et al., 2010).

In the marine environment, various authors recently demonstrated the presence of a clear relationship between the sea-surface temperature (SST) and the fish assemblages distribution, with deep implications in terms of species composition, all around the world (see Cheung et al., 2013). Studies in the Mediterranean Sea confirmed this pattern, both in terms of observations (Galil, 2008; Zenetos et al., 2012) and future projections (Ben Rais Lasram et al., 2010; Albouy et al., 2012).

Within this context, fishing activities are expected on one side to have synergistic effects with the climate-induced variations, on the other to be directly affected by the modifications (Brander, 2010, 2012; Sumaila et al., 2011; Worm and Branch, 2012). 
The presence of a strong relationship between landings and warming oceans has been demonstrated by several authors (Cheung et al., 2013; Pitcher and Cheung, 2013; Teixeira et al., 2013), confirming that the poleward movements of thermophilic species, due to the increasing SST, is affecting fisheries, both in qualitative and quantitative terms.

Regarding the level of spatial aggregation, recent studies are commonly based on the Large Marine Ecosystem (LME) scale (Cheung et al., 2013; Gamito et al., 2015), even if the effects of climate changes on fishery can be detected also a smaller scale (Gamito et al., 2012; Fortibuoni et al., 2015).

In relation to the processing of landings data, instead, there are two main tendencies, one adopting highly aggregated indicators, as the Mean Temperature of the Catch (MTC) proposed by Cheung et al. (2013), the other using the analysis at the species level (Tzanatos et al., 2014; Gamito et al., 2015).

Within this context, one of the rising questions is related to the role played by the spatial scale of analysis in determining the outputs. A second one is related to the effects of the data aggregation level, which can range from the single species to highly aggregated indicators, passing through an intermediate level of aggregation (e.g., by using functional categories).

These two issues are not trivial, mainly in relation to the opportunity to use such results to inform the management strategies to be adopted in order to cope with the climate changes effects on the fishery activities (Christensen et al., 2015).

Within this context, the Mediterranean Sea can represents a good case study, corresponding to one of the LMEs and being a sort of "small ocean" within a semi-enclosed basin, characterized by peculiar environmental conditions, such as the presence of strong gradients, and biodiversity hotspots (Lejeusne et al., 2010). Moreover, it can act as a cul de sac, avoiding the further northward migration of cold affinity species, due to the water warming (Ben Rais Lasram et al., 2010).

The aims of the present study are to investigate:

i) changes in the Mediterranean fisheries landings occurred in the last 40 years, in terms of incidence of cold, temperate and warm affinity species in fishery landings;

ii) if such changes can be explained by changes in seawater temperature;

iii) if the emerging patterns, in terms of temporal trend and the possible relationship with SST, can be generalized regardless the scale of basins.

\section{MATERIALS AND METHODS}

\section{Landings Data}

The time series of landings were reconstructed by using the General Fishery Commission for the Mediterranean (GFCM) capture database for the period 1970-2010 (available at http://www.fao.org/gfcm/data/capture-production-statistics/en/), according to the GFCM-FAO geographical division of the Mediterranean Sea in eight sub-areas (Figure 1), that represents the first level of spatial aggregation analysis. Spatial analysis has been carried out also aggregating data in three macro-areas (Western Med: Balearic, Sardinia, and Gulf of Lions; Northern
Med: Adriatic and Black Sea; Eastern/Southern Med: Ionian, Aegean and Levantine), by grouping the FAO areas based on geographic and climatic features (Figure 1), and finally at the level of the entire Mediterranean Sea.

The scientific name of targeted taxa was assigned to each commercial category, where possible, excluding cases of large categories including multispecies assemblages, such as "Fish," "Mollusks," etc., and highly migratory species, as bluefin tuna (Thunnus thynnus).

\section{Thermal Affinity Groups}

The thermal affinity of each species was assessed according to Pranovi et al. (2013). Occurrence data of each species recorded in the Northern hemisphere were retrieved from the Ocean Biogeographic Information System and Global Biodiversity Information Facility (OBIS/GBIF) online databases, which make available georeferenced records of living species, since the 1970 . Arbitrary latitudinal thresholds were set at $30^{\circ} \mathrm{N}$ (Southern limit of the Mediterranean basin) and $45^{\circ} \mathrm{N}$ (Northern limit of the basin, excluding the northernmost parts of the Adriatic and Black Sea), defining a Northern $\left(>45^{\circ} \mathrm{N}\right)$ "cold" zone, a Central (between 45 and $30^{\circ} \mathrm{N}$ ) "temperate" zone (typical of the Mediterranean Sea) and a Southern $\left(<30^{\circ} \mathrm{N}\right)$ "warm" zone. For each species, the thermal affinity attribution was based on whether its median latitude was comprised in the cold, temperate or warm zone (Pranovi et al., 2013).

The complete list of the species affinities is reported in the Table S1. The obtained classification resulted to be in good accordance with the thermal preferences list reported by Cheung et al. (2013) (see Figure S1).

Each group landings were then assessed as percentage of total landings, for the three spatial scales.

\section{Sea Surface Temperature (SST) Data}

The time series of the Sea Surface Temperature (SST) have been reconstructed by using the Extended Reconstructed Sea Surface Temperature (ERSST) online database (http://www.ncdc.noaa. gov/ersst). SST data are distributed as raster layers (regular grid with square cells of $2 \times 2$ degrees), and daily values have been mediated on the annual basis; annual estimates have been then mediated on the different spatial scales (entire Mediterranean basin, three macro-areas and eight FAO sub areas) of analysis, to obtain the opportune time series (see Figure S2).

\section{Landings-SST Relationship}

Generalized Additive Models (GAMs) have been used to investigate the landings-SST relationship. This method offers the opportunity to let the shape of the relationship between the response variables (landings) and predictors to be data driven (i.e., not a priori assumed), while allowing to control the degree of wiggliness (i.e., the complexity) (Wood, 2006). The choice of using GAMs is supported by the fact that they are relatively robust to multicollinearity issues (Dormann et al., 2013). In particular we fitted GAMs including a smoother for the trend (variable year), while we considered the contribution of water temperature (SST) only as a parametric linear term. 


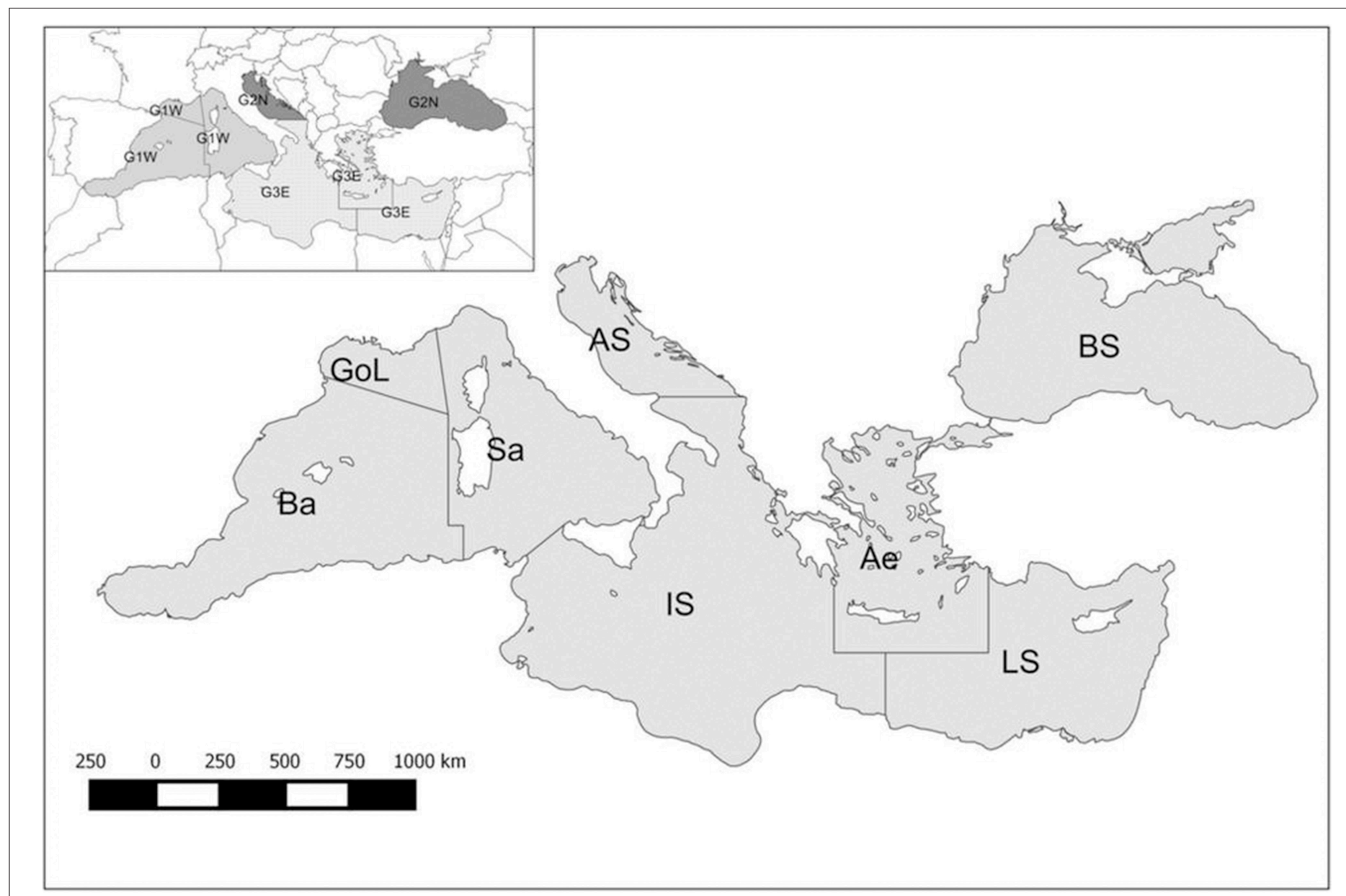

FIGURE 1 | The Mediterranean basin showing the eight FAO-areas and the aggregation in three macro-areas. Ba, Balearic Sea; GoL, Gulf of Lion; Sa, Sardinia; IS, Ionian Sea; AS, Adriatic Sea; Ae, Aegean Sea; LS, Levantine Sea; BS, Black Sea; G1W, macroarea West (mid-gray); G2N, macroarea North (dark-gray); G3E, macroarea East (light-gray).

GAMs have been fitted for three response variables (i.e., the percentage of cold, temperate and warm-water species). Several GAMs alternative formulations have been considered, by clustering models in two groups (Table 1): group A without including SST among the predictors, and group B accounting for SST influence. Predictors considered were, namely, year, SST, and a categorical variable representing the level of spatial aggregation. This was aimed at evaluating if SST plays a role in explaining trends of the different thermal categories. Within group $\mathrm{A}$ and $\mathrm{B}$, the alternative formulations allowed to investigate the role of the explaining variables at the different spatial scales, (basin, macroareas, sub-areas).The analysis was performed on the relative landings data, independently for each thermal affinity group. After a preliminary exploration of data distribution, models were fitted using Gaussian distribution with a linear link function in R environment (R Core Team, 2015, using the mgcv library (Wood, 2015) and the best model was selected according to the Akaike Information Criterion (AIC). In case of a lack of support for one single "best" model $(\triangle$ AIC smaller than 4 for the two models with the lower AIC values), predictions of different models were combined computing the weighted average predictions, using AIC weights (Burnham and Anderson, 2002).

\section{RESULTS}

The time series of landings for the three thermal affinity groups, for each FAO-area is reported in Figure 2. Several patterns can be recognized for the different groups in the each subareas, as the increasing of cold-water species in the Black Sea and Levantine and of warm-water species in the Balearic and Gulf of Lion; whereas, a decreasing trend of temperate-water species in the Adriatic Sea and of cold-water species in the Gulf of Lion and Balearic.

In relation to the spatial aggregation level, in all the three thermal affinity groups, the best model, selected based on the AIC (Table 2), resulted to be the model with the formulation B.4, i.e., the one for which landings depend on a temporal trend and an interaction of SST with the FAO area-factor (Table 1). Hence, the temporal trend for each thermal category is the same for the whole Mediterranean sea (the smoother of the GAM model), while the contribution of water temperature on the variation from such trend are explained by local (at sea basin level) SSTrelative catches relationship (the slope of such a relationship is sea basin-specific). The best models explain a large proportion of deviance for the three thermal categories, ranging from 83.8 
TABLE 1 | Models formulation.

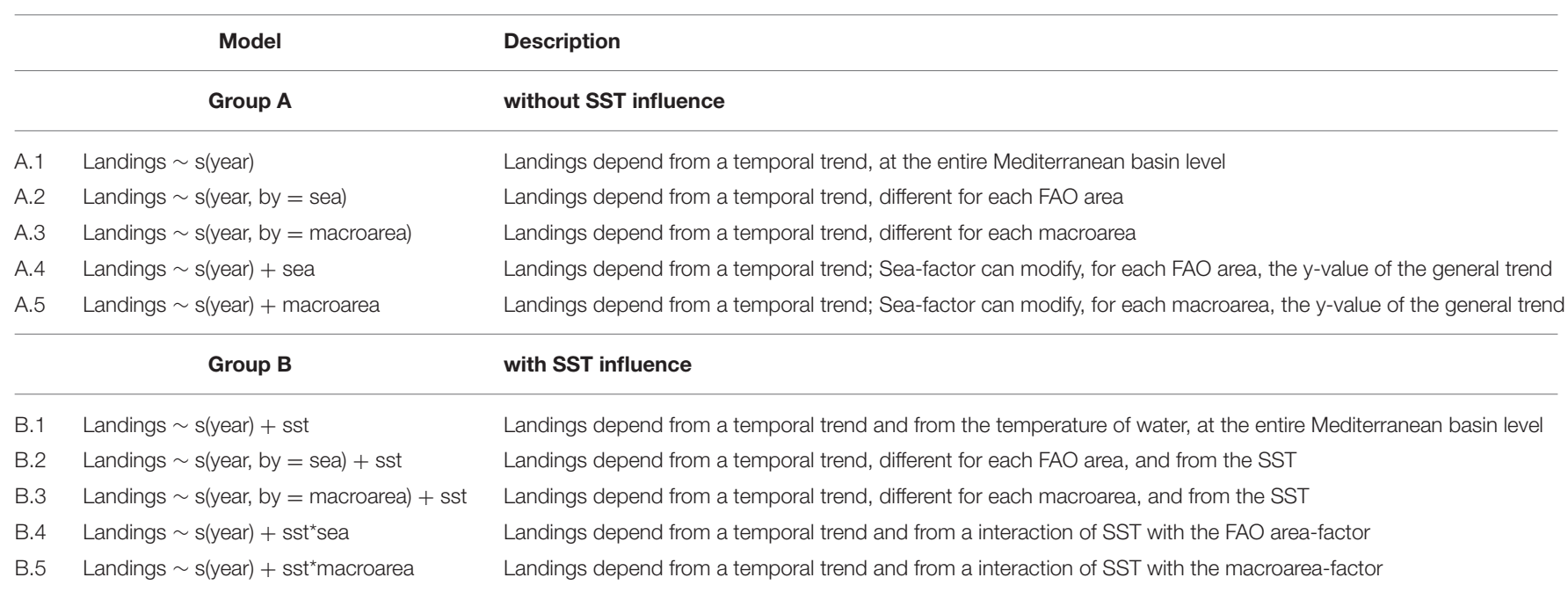

s, function to set up the model using spline based smooths; by, interaction between factor variable and smoother; *parametric interaction between variables; year, temporal trend; sea, FAO areas; macroarea, Western Med (Balearic, Sardinia, and Gulf of Lions); Northern Med (Adriatic and Black Sea), and Eastern/Southern Med (Ionian, Aegean and Levantine).

(temperate-water species; Table 2), to $88.0 \%$ (cold-water species; Table 2). It is worth to note that, even if the selected model structure (B.4) is the best performing, according to the chosen AIC criterion, other type of models show high levels of goodness of fit for all the three thermal categories (Table 2). These are for the model A.4 (Landings depend from a temporal trend; Seafactor can modify the outcome, for each macroarea) and the B.5 (Landings depend from a temporal trend and from a interaction of SST with the macroarea-factor).

The temporal trend over the 40 years time series, associated with the models for the three thermal categories is reported in Figure 3. At the FAO-areas level, cold-water species showed an increase over time with an almost linear pattern, temperatewater species a decrease over time following an almost linear pattern, while the warm-water ones present a weak, nonsignificant, trend (Figure 3A). Trends recorded at the macroarea and Mediterranean spatial scale resulted quite similar to those observed at the FAO-areas scale for cold and temperate-water category (Figures 3B,C), while it differed for warm-water species, in the case of the macroarea aggregation (Figure 3B). Indeed, only for the latter case, the estimated trend seems to have a negative pattern significantly different from zero (Figure 3B).

The comparison of the landings-SST relationship at the different spatial scales is reported in Figure 4. At the Mediterranean scale, temperate and warm-water species showed a positive relationship with SST, while cold-water species decreased for increasing temperatures (Figure 4A). This general pattern can be observed also at the macroarea scale (Figure 4B), at least for the Northern and West basins, even if there is a weaker positive effect of temperature on warm-water species. In the East one, warm-water species are characterized by a stronger positive relationship, while temperate and cold-water species decrease at higher water temperature values. The analysis highlighted the presence of contrasting patterns across the different FAO areas (Figure 4C): cold affinity species showed a negative relationship with temperature within all the FAO areas, with the exception of the Adriatic, Black Sea, and to a lesser extent for Aegean Sea (Figure 4C). The opposite pattern has been recorded for the temperate affinity species, showing a positive SST dependence for all the FAO areas, with the exception of the Adriatic, the Black Sea, and the Aegean Sea (Figure 4C). Finally, the warm affinity species showed for almost all the FAO areas a weak positive (but Adriatic Sea) relationship with SST, with Levant Sea being the one with the strongest signal (Figure 4C).

\section{DISCUSSION}

Ocean warming and overfishing represent the two main drivers affecting ecological processes in marine environments all around the world, often with synergistic effects (Möllmann and Diekmann, 2012). All this has to be taken into the account, as it is could be difficult to disentangle them when analyzing temporal patterns of nekton assemblages. In order to assess this kind of effects, usually a backward approach is utilized. Within this context, in many cases the only source of data to reconstruct the time series are fishery-dependent data, as landings from official statistics. The representativeness of catch data in terms of the real community biomass is object of open debate, being affected by unreported/illegal catches, missing entire compartments or key species simply not targeted by fisheries (Pauly et al., 2013). However, previous studies demonstrated that landings could represent a reliable proxy for understanding changes in exploited marine communities (sensu Pauly et al., 2013), and can be used to assess climate effects (Pranovi et al., 2013; Tsikliras and Stergiou, 2014; Tzanatos et al., 2014). A major concern about the use of landings data is related to their strong dependence by the fishing effort, which usually remains not known, especially in terms of variations during the time. In the present study, this issue has been partially addressed by using relative data (proportion 


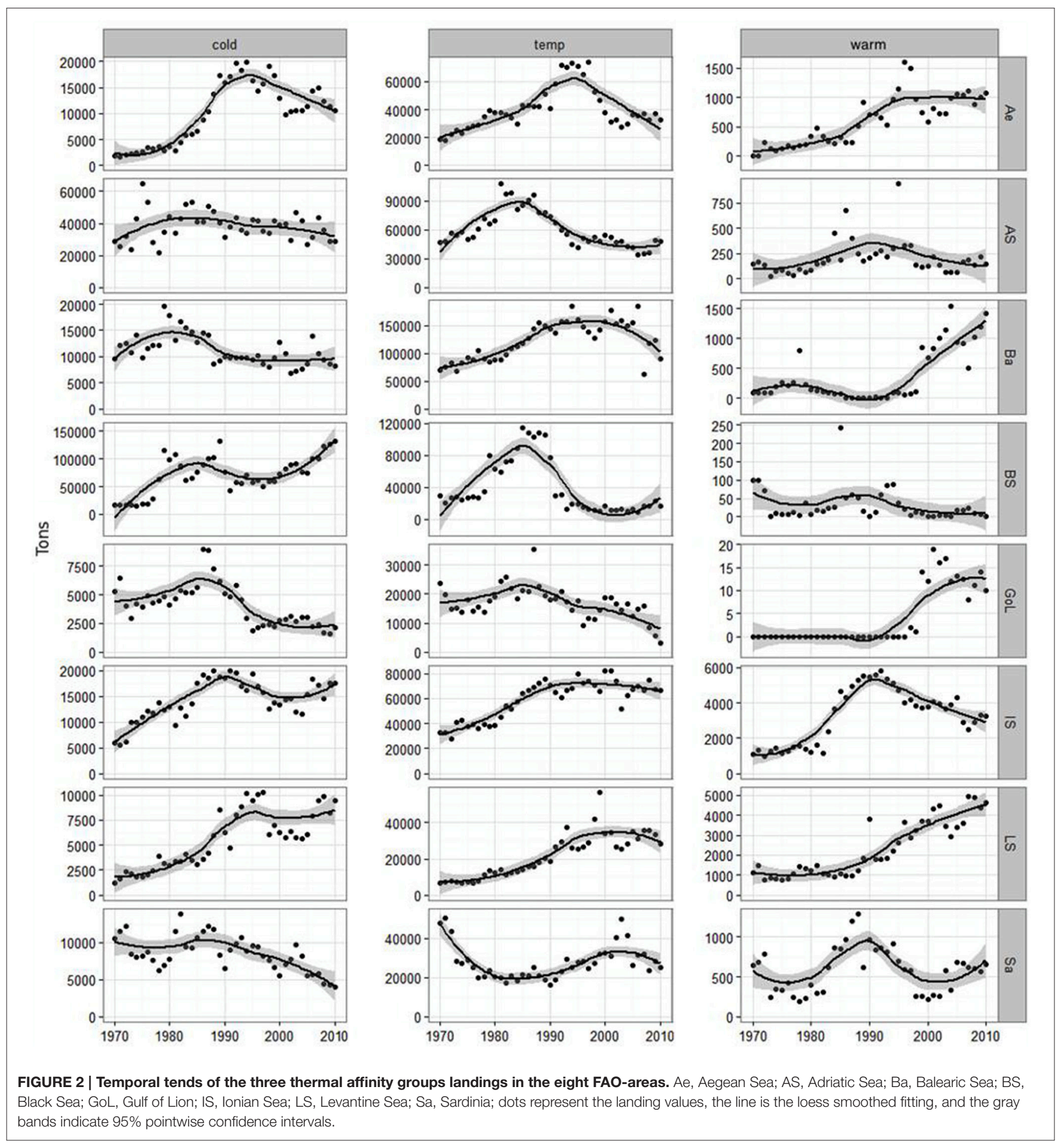

of each thermal affinity group), instead of the absolute values, which are directly affected by modifications of the fishing pressure. The absolute landings values remained important in the phase of explanation of obtained results, since working on the relative contributions required the assessment of which category is driving the observed patter. With direct reference to the FAO database, some concerns have been raised regarding the quality of data until 1980 (Tzanatos et al., 2014). Preliminary comparative analyses performed on dataset with the entire series (1970-2010) or the reduced one (without the first decade), excluded, however, differences in terms of outputs (results not shown).

The multi-scale approach adopted, allowed to show that the trends of the landing composition are general (valid for the 
TABLE 2 | Landings-SST model selection parameters, for the three thermal affinity groups.

\begin{tabular}{|c|c|c|c|c|c|c|c|c|c|}
\hline \multirow[t]{2}{*}{ Model } & \multicolumn{3}{|c|}{ Cold-water species } & \multicolumn{3}{|c|}{ Temperate-water species } & \multicolumn{3}{|c|}{ Warm-water species } \\
\hline & AIC & $R^{2}$ & Explained deviance & AlC & $R^{2}$ & Explained deviance & AIC & $R^{2}$ & Explained deviance \\
\hline A. 1 & 2850.06 & 0.01 & 0.02 & 2832.02 & 0.02 & 0.02 & 1610.52 & 0.00 & 0.00 \\
\hline A.2 & 2820.18 & 0.12 & 0.14 & 2799.03 & 0.13 & 0.15 & 1610.10 & 0.03 & 0.06 \\
\hline A.3 & 2840.33 & 0.05 & 0.06 & 2822.02 & 0.05 & 0.06 & 1613.36 & 0.00 & 0.01 \\
\hline A.4 & 2345.73 & 0.79 & 0.80 & 2351.71 & 0.78 & 0.78 & 973.42 & 0.86 & 0.86 \\
\hline A.5 & 2697.42 & 0.38 & 0.39 & 2709.16 & 0.33 & 0.33 & 1403.67 & 0.47 & 0.48 \\
\hline B.1 & 2605.84 & 0.53 & 0.54 & 2657.92 & 0.42 & 0.43 & 1426.06 & 0.43 & 0.44 \\
\hline B.2 & 2513.85 & 0.66 & 0.67 & 2584.69 & 0.55 & 0.57 & 1414.71 & 0.47 & 0.49 \\
\hline B.3 & 2578.18 & 0.57 & 0.58 & 2636.37 & 0.46 & 0.47 & 1428.61 & 0.43 & 0.44 \\
\hline B.4 & 2260.13 & $\underline{0.84}$ & $\underline{0.85}$ & 2272.77 & $\underline{0.83}$ & $\underline{0.84}$ & $\underline{956.36}$ & $\underline{0.87}$ & $\underline{0.88}$ \\
\hline B.5 & 2521.45 & 0.64 & 0.65 & 2541.48 & 0.60 & 0.61 & 1134.30 & 0.77 & 0.78 \\
\hline
\end{tabular}

underlined is the best model for each group.

whole Mediterranean), but that the best models include a local correction term. In particular, our results highlighted the role of the SST as explanatory variable, confirming it as one of the most important drivers affecting landings composition (Cheung et al., 2013; Tzanatos et al., 2014; Gamito et al., 2015). The spatial scale of analysis revealed to be a critical issue in determining final outputs. Even if the recorded temporal trend is the same, at least for cold and temperate-water species, at all the three tested spatial scales, the best model choice indicated that the local conditions can dramatically modify the relationship, when the SST is taken into consideration. The selection of the models of the type B.4 (i.e., the ones at the finer spatial scale) for the three thermal categories implies that the landings-SST relationship is basin specific. Indeed, for each thermal category the slope of the impact of SST on the expected catches can be different in terms of sign and magnitude for the different basins. The strength (i.e., the slope) and, more important, the direction (i.e., the sign) of such a relationship, indeed, depends on local conditions, showing marked differences among the considered areas.

Cold affinity species confirmed to be negatively affected by the water warming, even if in the coldest areas of the Mediterranean Sea, namely the Adriatic and Black Seas, which host boreal affinity species (e.g., sprat and plaice), the relationship resulted to be positive. In these areas, being the coldest of the entire basin, we hypothesize that these species could be able to exploit warmer conditions (e.g., in terms of life cycle) and their effects on the ecosystems (e.g., the increase in productivity) or that the increase in SST has still not reached critical values. All this would be in accordance with Gamito et al. (2015), which reported an increase in catches from coldest LMEs, in warmer seasons.

Temperate affinity species, on the contrary, showed a positive relationship with the SST, in almost all FAO areas with the exception of the coldest ones (Adriatic and Black Seas, and marginally Aegean Sea). This would suggest that in the Mediterranean Sea temperate-water species could still cope with the SST increasing level, without significant negative effects. In order to explain the different patterns recorded in the Adriatic and Black Sea, it is necessary to look at absolute trends of landings. In the Adriatic Sea, the both groups showed a decline, but the temperate-water species curve is steeper than that of the cold-water one; whereas in the Black Sea, the cold-water species showed an increase during the last years. In ecological terms, this could be probably explained by competition and/or trophic interactions between the species belonging to the cold and temperate-water groups.

Finally, the warm affinity species showed a positive relationship with the SST in all the Mediterranean FAO areas, even if not so strong as expected, with the exception of the Levantine Sea, which represents the warmest area. However, even in the latter area, the warm-water species represent a relatively small proportion of the total catches. It is worthy to note that this result is not affected by lessepsian species (immigrant organisms from the Red Sea through the Suez Canal), since these are not yet officially recorded in the GFCM database (Tsikliras and Stergiou, 2014).

Recently, Tsikliras and Stergiou (2014) reported for the Mediterranean Sea, analyzed for three sub-basins (Western, Central and Eastern), a MTC increasing rate higher than those reported for other LMEs, suggesting a significant increase in the contributing of warm-water species and a decrease of the cold-water ones. In the present study, although confirming the general relationship, we demonstrated that changing the spatial scale of analysis the situation can be quite different, which could affect also the MTC trend, as reported for the Adriatic Sea by Fortibuoni et al. (2015).

At global scale, climate changes can be considered as the major source of impact for fisheries. Within this context, there is a need to improve the science capability in assessing the future status of fish stocks and ecosystems in order to support the development of policies that minimize damaging impacts and maximize opportunities (Pecl et al., 2014). At present, however, this remains a not completely realized objective and only retrospective analysis of temporal trends can be performed. Analytic tool adopted so far, mainly finalized to the pattern recognition, seems to be able to record some of the changes that we are experiencing. 


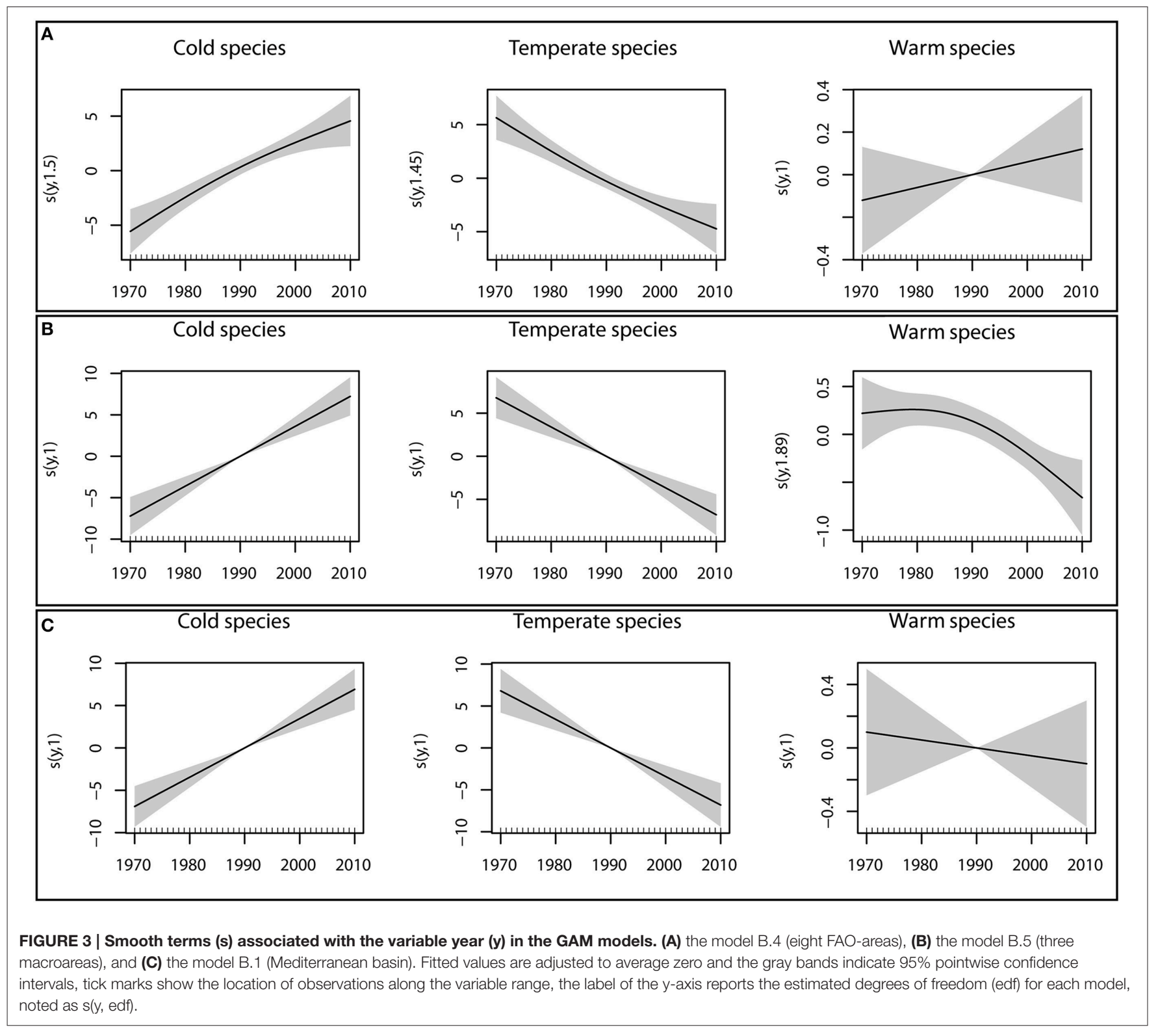

Nevertheless, some of the results could be influenced by the issues that should to be taken into consideration, in particular related to the level of aggregation of the data and the spatial scale of analysis. The use of the highly aggregated indicators, as the MTC, and large spatial scale, as the Large Marine Ecosystems (LMEs), could catch general patterns but mask local/regional patterns. On the opposite the analysis at the lowest taxonomic level i.e., the species, even if often allows a more sound ecological interpretation, could be difficult to be aggregated in common patterns, being the responses of each species quite different, with several different factors (e.g., life cycles and fishing effort) that can become relevant (Pecl et al., 2014). The medium-aggregation level here adopted could be optimal to detect the climaterelated effects, while letting a more detailed (e.g., species-specific) analysis as a posteriori interpretation of the results. An additional advantage of this aggregation level is the one of an adequate level of robustness, as the thermal affinity groups are expected to be less influenced by the fishing effort, since fishermen don't target for cold, temperate or warm-water species. Moreover, testing the effects of climate on landings at different spatial scale can reveal non-obvious local patterns, which could be very important to provide information for the management of the exploited resources. The possible synergistic/confounding effects of other drivers (both natural and anthropogenic), possibly affecting landings, such as productivity, overfishing, market demand (see for example, Marcos et al., 2015) remains, however, a question to be further explored, even if the approach here adopted allow us to at least partially to cope with this, also taking into the account that often reliable time series for these drivers are not available. 


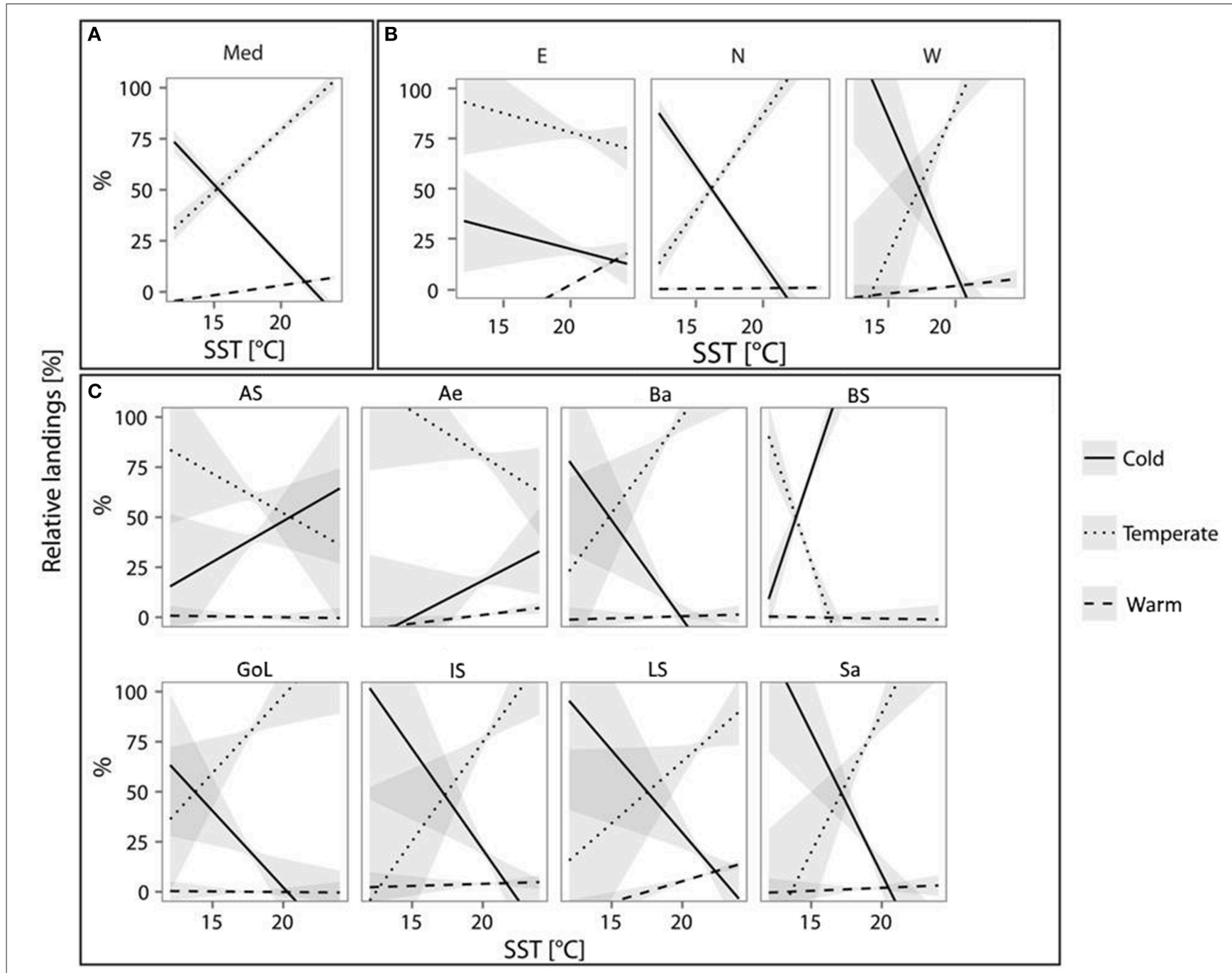

FIGURE 4 | Landings -SST relationship for each thermal affinity group, at different spatial scale of analysis. (A) Mediterranean basin, (B) macroareas (C) FAO areas; AS, Adriatic Sea; Ae, Aegean Sea; Ba, Balearic Sea; BS, Black Sea; GoL, Gulf of Lion; IS, Ionian Sea; LS, Levantine Sea; Sa, Sardinia; landings are expressed as percentage of total catches.

\section{CONCLUSIONS}

In conclusion, the study confirmed the important role of the water warming in explaining the temporal trends of landings, according to the thermal affinity of the component species. The influence of SST on landings, however, resulted to be different for the three groups and across the Mediterranean basin. Finally, the importance of the spatial scale of analysis has been showed, being the best structure of model explaining such a relationship the one encompassing the area specific SST-landings relationship.

This kind of analysis could be useful to monitor how global warming is affecting marine ecosystem services in the framework of the EU Strategy on adaptation to climate change and to inform management strategies, also in terms of renewable resources exploitation. Within this context, it is important to consider that the spatial scale of management strategies/plans is the regional one. In order to be useful for informing management activities, this kind of analysis need therefore to be carried out at a consistent spatial scale, to avoid misleading consequences.

\section{AUTHOR CONTRIBUTIONS}

All authors listed, have made substantial, direct and intellectual contribution to the work, and approved it for publication.

\section{SUPPLEMENTARY MATERIAL}

The Supplementary Material for this article can be found online at: http://journal.frontiersin.org/article/10.3389/fmars. 2016.00143 


\section{REFERENCES}

Albouy, C., Guilhaumon, F., Araujo, M. B., Mouillot, D., and Leprieur, F. (2012). Combining projected changes in species richness and composition reveals climate change impacts on coastal Mediterranean fish assemblages. Glob. Change Biol. 18, 2995-3003. doi: 10.1111/j.1365-2486.2012.02772.x

Ben Rais Lasram, F., Guilhaumon, F., Albouy, C., Somot, S., Thuiller, W., and Mouillot, M. (2010). The Mediterranean Sea as a "cul-de-sac" for endemic fishes facing climate change. Glob. Change Biol. 16, 3233-3245. doi: 10.1111/j.13652486.2010.02224.x

Brander, K. (2010). Impacts of climate change on fisheries. J. Mar. Syst. 79, 389-402. doi: 10.1016/j.jmarsys.2008.12.015

Brander, K. (2012). Climate and current anthropogenic impacts on fisheries. Clim. Change 119, 9-21. doi: 10.1007/s10584-012-0541-2

Burnham, K. P., and Anderson, D. R. (2002). Model Selection and Multimodel Inference. A Practical Information-Theoretic Approach. New York, NY: Springer.

Cheung, W. W. L., Watson, R., and Pauly, D. (2013). Signature of ocean warming in global fisheries catch. Nature 497, 365-368. doi: 10.1038/nature12156

Christensen, V., Colla, M., Buszovski, J., Cheung, W. W. L., Frolicher, T., Steenbeek, J., et al. (2015). The global ocean is an ecosystem: simulating marine life and fisheries. Glob. Ecol. Biogeogr. 24, 507-517. doi: 10.1111/geb. 12281

Dormann, C. F., Elith, J., Bacher, S., Buchmann, C., Carl, G., Carré, G., et al. (2013). Collinearity: a review of methods to deal with it and a simulation study evaluating their performance. Ecography 36, 27-46. doi: 10.1111/j.16000587.2012.07348.x

Fortibuoni, T., Aldighieri, F., Giovanardi, O., Pranovi, F., and Zucchetta, M. (2015). Climate impact on Italian fisheries (Mediterranean Sea). Reg. Environ. Change 15, 931-937. doi: 10.1007/s10113-015-0781-6

Galil, B. S. (2008). Taking stock: inventory of alien species in the Mediterranean Sea. Biol. Inv. 11, 359-372. doi: 10.1007/s10530-008-9253-y

Gamito, R., Costa, M. J., and Cabral, H. N. (2015). Fisheries in a warming ocean: trends in fish catches in the large marine ecosystems of the world. Reg. Environ. Change 15, 57-65. doi: 10.1007/s10113-014-0615-y

Gamito, R., Teixeira, C. M., Costa, M. J., and Cabral, H. N. (2012). Climateinduced changes in fish landings of different fleet components of Portuguese fisheries. Reg. Environ. Change 13, 413-421. doi: 10.1007/s10113-0120358-6

Gilman, S. E., Urban, M. C., Tewskbury, J., Gilchrist, G. W., and Holt, R. D. (2010). A framework for community interactions under climate change. Tree 25, 325-331. doi: 10.1016/j.tree.2010.03.002

Hoegh-Guldberg, O., and Bruno, J. F. (2010). The impact of climate change on the world's marine ecosystems. Science 328, 1523-1528. doi: 10.1126/science. 1189930

Lejeusne, C., Chevaldonne, P., Pergent-Martini, C., Boudoruesque, C. F., and Perez, T. (2010). Climate change effects on a miniature ocean: the highly diverse, highly impacted Mediterranean Sea. Tree 25, 250-260. doi: 10.1016/ j.tree.2009.10.009

Marcos, C., Torres, I., Lopez-Capel, A., and Perez-Ruzafa, A. (2015). Long term evolution of fisheries in a coastal lagoon related to changes in lagoon ecology and human pressures. Rev. Fish Biol. Fish. 25, 689-713. doi: 10. 1007/s11160015-9397-7

Möllmann, C., and Diekmann, R. (2012). Marine ecosystem regime shifts induced by climate and overfishing: a review for the Northern Hemisphere. Adv. Ecol. Res. 47, 303-347. doi: 10.1016/B978-0-12-398315-2.00004-1
Pauly, D., Hilborn, R., and Branch, T. A. (2013). Fisheries: does catch reflect abundance? Nature 494, 303-306. doi: 10.1038/494303a

Pecl, G. T., Ward, T., Doubleday, Z., Clarke, S., Day, J., Dixon, C., et al. (2014). Rapid assessment of fisheries species sensitivity to climate change. Clim. Change 127, 505-520. doi: 10.1007/s10584-014-1284-z

Pitcher, T. J., and Cheung, W. W. L. (2013). Fisheries: hope or despair? Mar. Poll. Bull. 74, 506-516. doi: 10.1016/j.marpolbul.2013.05.045

Pranovi, F., Caccin, A., Franzoi, P., Malavasi, S., Zuchetta, M., and Toricelli, P. (2013). Vulnerability of artisanal fisheries to climate change in the Venice Lagoon. J. Fish Biol. 83, 847-864. doi: 10.1111/jfb.12124

R Core Team (2015). R: A Language and Environment for Statistical Computing. Vienna: R Foundation for Statistical Computing. Available Online at: http:// www.R-project.org

Sumaila, U. R., Cheung, W. W. L., Lam, V. W. Y., Pauly, D., and Herrik, S. (2011). Climate change impacts on the biophysics and economics of world fisheries. Nat. Clim. Change 1, 449-456. doi: 10.1038/nclimate1301

Teixeira, C. M., Gamito, R., Leitao, F., Cabral, H., Erzini, K., and Costa, M. J. (2013). Trends in landings of fish species potentially affected by climate change in Portuguese fisheries. Reg. Environ. Change 14, 657-669. doi: 10.1007/s10113013-0524-5

Tsikliras, A., and Stergiou, K. (2014). Mean temperature of the catch increases quickly in the Mediterranean Sea. Mar. Ecol. Prog. Ser. 515, 281-284. doi: 10.3354/meps11005

Tzanatos, E., Raitsos, D., Triantafyllou, G., Somarakis, S., and Tsonis, A. A. (2014) Indications of a climate effect on Mediterranean fisheries. Clim. Change 122, 41-54. doi: 10.1007/s10584-013-0972-4

Wood, S. N. (2006). Generalized Additive Models: An Introduction. R. Boca Raton, FL: Chapman and Hall/CRC.

Wood, S. N. (2015). mgcv: GAMs with GCV Smoothness Estimation and GAMMs by REML/PQL. R Package Version 1.8-6. Available online at: http://CRAN.Rproject.org $/$ package $=\mathrm{mgcV}$

Woodward, G., Benstead, J. P., Beveridge, O. S., Blanchard, J., Brey, T., Brown, L. E., et al. (2010). Ecological networks in a changing climate. Adv. Ecol. Res. 42, 71-138. doi: 10.1016/B978-0-12-381363-3.00002-2

Worm, B., and Branch, T. A. (2012). The future of fish. Tree 27, 594-599. doi: 10.1016/j.tree.2012.07.005

Zenetos, A., Ballesteros, E., and Veralque, M. (2012). Alien species in the Mediterranean Sea by 2012. A contribution to the application of European Union's Marine Strategy Framework Directive (MSFD). Part 2. Introduction trends and pathways. Medit. Mar. Sci. 13, 328-352. doi: 10.12681/mms.327

Conflict of Interest Statement: The authors declare that the research was conducted in the absence of any commercial or financial relationships that could be construed as a potential conflict of interest.

The handling Editor declares that, despite being affiliated to the same institution and collaborating with the reviewer TB, the review process was handled objectively and no conflict of interest exists.

Copyright (c) 2016 Pranovi, Anelli Monti, Brigolin and Zucchetta. This is an openaccess article distributed under the terms of the Creative Commons Attribution License (CC BY). The use, distribution or reproduction in other forums is permitted, provided the original author(s) or licensor are credited and that the original publication in this journal is cited, in accordance with accepted academic practice. No use, distribution or reproduction is permitted which does not comply with these terms. 